\title{
Marek Disease
}

National Cancer Institute

\section{Source}

National Cancer Institute. Marek Disease. NCI Thesaurus. Code C84884.

A viral infection in chickens caused by the herpes virus. It is characterized by tissue

lymphocytic infiltration, limb paralysis and development of tumors. 